\title{
FORMAÇÃO DE PROFESSOR E PROFISSIONALISMO: REFLEXÕES ACERCA DA AVALIAÇÃO EXTERNA
}

\author{
SANTOS, Maria Adriana Borges dos (Brasil, Ceará, Fortaleza $)^{1 *}$; \\ FERREIRA, Heraldo Simões (Brasil, Ceará, Fortaleza) ${ }^{1^{* *}}$; \\ SIMÕES, Luiza Lúlia Feitosa (Brasil, Ceará, Fortaleza) ${ }^{1{ }^{1+2}}$ \\ ${ }^{1}$ Universidade Estadual do Ceará \\ ORCID ID: https://orcid.org/0000-0003-2090-2864 \\ ORCID ID: https://orcid.org/0000-0003-1999-7982 \\ ORCID ID: https://orcid.org/0000-0002-2035-037X*
}

\begin{abstract}
RESUMO
O objetivo deste estudo é analisar o posicionamento dos docentes de duas escolas públicas dos municípios de Fortaleza e de Maracanaú sobre as implicações da Prova Brasil/Índice de Desenvolvimento da Educação Básica no currículo escolar e no profissionalismo do professor. Trata-se de uma abordagem qualitativa cujo método selecionado consistiu em estudo de caso. Duas escolas públicas localizadas no estado do Ceará foram o cenário. Os sujeitos foram oito professoras do 5o ano do Ensino Fundamental. Para a coleta dos dados, realizou-se uma entrevista com os envolvidos. Para a análise dos dados, recorreu-se à análise temática de Minayo. Como principais resultados dialogados, aponta-se que a avaliação externa Prova Brasil/Índice de Desenvolvimento da Educação Básica apresenta-se como dispositivo que induz a um currículo prescrito e reducionista, comprometendo a autonomia e o profissionalismo do professor e ainda subordinando a qualidade da educação ao rendimento do aluno.
\end{abstract}

\section{PALAVRAS-CHAVE}

Profissionalismo. Avaliação externa. Atividades curriculares.

\section{TEACHER TRAINING AND PROFESSIONALISM:}

\section{REFLECTIONS ABOUT EXTERNAL EVALUATION}

\begin{abstract}
The aim of this study is to analyze the placement of teachers of two public schools in the municipalities of Fortaleza and Maracanaú on the implications of proof-Brazil/IDEB in the school curriculum and in teacher's professionalism. This is a qualitative approach whose selected method consisted of a case study, the scene were two public schools located in the State of Ceará, the subjects were eight teachers of the 5th grade of elementary school, for data collection was held an interview with those involved. For analysis of the data we have from the thematic analysis of Minayo. Main spoken results, point to the external evaluation proof-Brazil/IDEB is device that induces a prescribed curriculum and reductionist, compromises the independence and professionalism of teacher and still makes the quality of education to the the student's income.
\end{abstract}

\section{KEYWORDS}

Professionalism. External evaluation. Curricular activities. 


\title{
FORMACIÓN DEL PROFESORADO Y PROFESIONALIDAD: REFLEXIONES SOBRE LA EVALUACIÓN EXTERNA
}

\begin{abstract}
RESUMEN
El objetivo de este estudio es analizar el posicionamiento de los docentes de dos escuelas públicas de los municipios de Fortaleza y de Maracanaú sobre las implicaciones de la Prueba Brasil / Índice de Desarrollo de la Educación Básica en el currículo escolar y en el profesionalismo del profesor. Se trata de un enfoque cualitativo cuyo método seleccionado consistió en un estudio de caso. Dos escuelas públicas ubicadas en el estado de Ceará fueron el escenario. Los sujetos fueron ocho profesoras del $5^{\circ}$ año de la Enseñanza Fundamental. Para la recolección de los datos, se realizó una entrevista con los involucrados. Para el análisis de los datos, se recurrió al análisis temático de Minayo. Como principales resultados dialogados, se apunta que la evaluación externa Prueba Brasil / Índice de Desarrollo de la Educación Básica se presenta como dispositivo que induce a un currículo prescrito y reduccionista, comprometiendo la autonomía y el profesionalismo del profesor y aún subordinando la calidad de la educación al rendimiento del alumno.
\end{abstract}

PALABRAS CLAVE

Profesionalismo. Evaluación externa. Actividades curriculares.

\section{INTRODUÇÃO}

Nas últimas décadas do século XX e início do século XXI, a educação brasileira vem passando por profundas mudanças, uma delas é registrada com a Conferência Mundial sobre Educação para Todos, em 1990, na Tailândia. Essa Conferência gera mudanças no cenário político, econômico, social e educacional do mundo, tendo como destaque assegurar a aprendizagem para crianças, para jovens e para adultos. Na visão de Bonfim (2010), são influências internacionais que se refletem no sistema neoliberal brasileiro, gerando maior instabilidade no campo educacional e consequentemente responsabilizando escolas e professores pela baixa qualidade da aprendizagem dos alunos. Esse quadro favorece a implementação de políticas públicas que visem à produtividade como meta e à avaliação como controle.

Mesmo antes desse cenário, em 1986, as discussões iniciais sobre a execução de um sistema de avaliação em larga escala, no Brasil, já existiam com o Projeto Edurural, financiado com recursos do Banco Mundial (BRASIL, 2011).

O Brasil manifesta a necessidade de avaliar a qualidade do ensino para a geração de políticas públicas que providenciem subsídios para a aprendizagem dos 
alunos. Tal necessidade é conjecturada com a avaliação externa, que é empregada e padronizada, no intuito de obter resultados possíveis de comparar em rede as escolas e definir políticas educacionais e ainda conceder bonificação salarial aos docentes por desempenho do resultado dos alunos.

Os sistemas de avaliação da educação são compostos por: Programa Internacional de Avaliação de Alunos (Pisa); Exame Nacional do Ensino Médio (Enem); Exame Nacional para Certificação de Competências de Jovens e Adultos (Encceja); Provinha Brasil; e Sistema de Avaliação da Educação Básica (Saeb), que é integrado pela Avaliação Nacional da Educação Básica (Aneb) e pela Avaliação Nacional do Rendimento Escolar (Anresc) (BRASIL, 2011).

A Aneb vem sendo implementada na avaliação desde o ano de 1995 e avalia a qualidade, a equidade e a eficiência da educação brasileira nos sistemas e nas redes de ensino através da aplicação de questionários.

Já a Anresc, estabelecida de forma sistemática com a Portaria № 69, de 4 de maio de 2005, é conhecida como Prova Brasil e acontece a cada dois anos, avaliando habilidades em Língua Portuguesa, com foco na leitura, e Matemática, com foco na resolução de problemas. É aplicada somente com alunos de $5^{\circ}$ e $9^{\circ}$ anos de escolas públicas que tenham mais de 20 estudantes matriculados por série alvo da avaliação.

Desse modo, a Prova Brasil expande o alcance dos resultados oferecidos pela Aneb, fornecendo médias de desempenho para o Brasil, regiões e unidades, os quais juntos compõem o Sistema de Avaliação da Educação Básica, portanto tanto a Prova Brasil quanto o Saeb são exames que se complementam.

Conforme Brasil (2011) e Dalben (2005), a Prova Brasil tem dois objetivos centrais: a) contribuir para a melhoria da qualidade do ensino, reduzir as desigualdades e democratizar a gestão do ensino público; b) buscar o desenvolvimento de uma cultura avaliativa que estimule o controle social sobre os processos e os resultados do ensino.

O governo federal em 2007 cria o Plano de Desenvolvimento Educacional (PDE) para auxiliar na implementação desses objetivos e da melhoria da qualidade da educação. Esse plano, juntamente com o Ministério de Educação (MEC) e o Instituto Nacional de Estudos e Pesquisas Educacionais Anísio Teixeira (Inep), institui o sistema de avaliação através do Índice de Desenvolvimento da Educação Básica (Ideb), no

Educação \& Formação, Fortaleza, v. 4, n. 11, p. 161-178 maio/ago. 2019 
referido ano, formulado para medir a qualidade do aprendizado nacional e estabelecer metas para a melhoria do ensino (BRASIL, 2017).

O Ideb funciona como um denominador da qualidade da educação básica em todos os estados, os municípios e as escolas no Brasil através de dois indicadores: a) fluxo escolar (passagem dos alunos pelas séries sem repetir, avaliados pelo Programa Educacenso); e b) desempenho dos estudantes (avaliado pela Prova Brasil nas áreas de Língua Portuguesa e Matemática) (BRASIL, 2011). Para este estudo, iremos considerar apenas esse último fator.

Nesse enfoque, os resultados da Prova Brasil são agrupados aos do Ideb, consistindo em um sistema integrado de avaliação em larga escala. Neste estudo, adotamos o termo Prova Brasil/ldeb. Essa avaliação tem se manifestado como tema recorrente em âmbito educacional, em especial na escola básica, que, de forma geral, possui na avaliação da aprendizagem sua referência central.

A terminologia "avaliação" pode assumir diversos focos e diversos sentidos, como aprendizagem, como formação de professor, como desempenho dos alunos e dos professores, como currículo e como políticas. Assim, cabe a nós esclarecer que esta pesquisa trata não da avaliação de aprendizagem realizada na escola pelo professor em sala de aula, mas da avaliação externa, realizada pelos órgãos do Estado por meio dos sistemas de avaliação em massa das redes de ensino público, conforme já foi explicitado.

Assim como sugere Freitas (2005), o Ideb visa à melhoria da qualidade da educação por meio de um sistema de prestação de contas fundamentado na bonificação para professores, a partir dos resultados obtidos pelos alunos. Isso faz com que escolas e docentes se sintam responsáveis pelo desempenho dos discentes, consolidando um tipo de política chamada de responsabilização em torno da avaliação educacional.

No que se refere à carreira profissional, Saviani (2007) analisa que não faz sentido vincular o pagamento do piso salarial aos resultados dos exames. Assim, para o autor há uma compreensão negativa sobre a questão salarial que repercutirá no interior das salas de aula, contaminando o trabalho pedagógico dos professores e interferindo também no ânimo dos alunos.

Nas interfaces da avaliação externa, consideramos importante pensar nas práticas pedagógicas do professor, nas implicações na escola, na organização do 
trabalho docente, nos programas escolares, nos discursos, nos objetivos, nos conteúdos e nos métodos mobilizados através do currículo ao longo da carreira dos profissionais.

Consoante essa perspectiva de currículo, dialogamos acerca das proposições da investigação, que segue ancorada nos pressupostos de Sacristán (2000), ao compreender o currículo como uma multiplicidade de relações, implícitas, em diversos âmbitos, que vão da prescrição à ação, das decisões administrativas às práticas pedagógicas dos professores. Para compreendê-lo e principalmente para elaborá-lo e implementá-lo de modo a transformar o ensino, é preciso refletir sobre o cotidiano da escola.

$\mathrm{O}$ interesse em investigar essa temática surge por vivenciarmos diariamente em ambiente escolar a dinâmica da busca contínua pelo progresso do rendimento dos alunos, intensificada quando se aproximam os períodos de avaliação externa, levando os professores a evidenciar nas práticas pedagógicas os conteúdos da Prova Brasil//deb.

Outro fator que justifica esta investigação é a escassez de produção científica identificada ao realizar busca nos periódicos da Coordenação de Aperfeiçoamento de Pessoal de Nível Superior (Capes), utilizando os descritores avaliação externa e profissionalismo. Somente 24 trabalhos foram encontrados, sendo somente cinco sobre avaliação, mas do Ensino Superior, e não referente à Educação Básica, os demais aludem a áreas da Saúde e/ou a assuntos que não sejam da área da Educação.

Ao utilizarmos o descritor avaliação externa entre aspas, surgiram 168 artigos, no entanto, ao analisarmos os resumos, identificamos apenas cinco trabalhos que remetiam ao profissionalismo do professor, dos quais nenhum localizado no estado do Ceará. São eles: Os impactos da avaliação externa sobre o trabalho de professores na rede estadual paulista; Efeitos da política nacional de avaliação em larga escala na gestão política e pedagógica de escolas municipais de Porto Alegre: explorando relações e utilizações; Notas psicanalíticas: os discursos contemporâneos acerca da avaliação educacional no Brasil; Impactos da avaliação externa nas políticas de gestão educativa; e Os impactos da avaliação em larga escala nos currículos escolares.

Ao realizarmos a leitura de tais artigos, verificamos que as avaliações têm gerado uma hierarquização e uma classificação entre as instituições e os profissionais e têm influenciado de maneira negativa o currículo escolar e a sua sistemática de funcionamento. Esses achados nos levam a questionar os conhecimentos que devem

Educação \& Formação, Fortaleza, v. 4, n. 11, p. 161-178 maio/ago. 2019 
ser ensinados nas escolas, a partir das concepções de mundo, de homem, de sociedade e da qualidade a que se aspira.

Dessa feita, formulamos o seguinte problema da atividade investigativa: qual 0 posicionamento dos docentes de duas escolas públicas dos municípios de Fortaleza e de Maracanaú sobre as implicações no currículo escolar e na sua formação profissional, impelidas pela Prova Brasil//deb?

O estudo revela-se importante para professores, para gestores, para avaliadores e para pesquisadores, pois poderá propor reflexão para repensar o sistema de avaliação educacional em nível de políticas públicas e servir de embasamento teórico, implicando na melhoria da qualidade da educação e no processo de formação docente. Assim sendo, o objetivo deste estudo é analisar o posicionamento dos docentes de duas escolas públicas dos municípios de Fortaleza e Maracanaú, no Ceará, sobre as implicações da Prova Brasil//deb no currículo escolar e no profissionalismo do professor.

\section{PERCURSO METODOLÓGICO}

A pesquisa, que se classifica como uma abordagem qualitativa do tipo estudo de caso, foi desenvolvida em duas escolas públicas, sendo uma do município de Fortaleza e outra do município de Maracanaú, no Ceará. Os lócus foram escolhidos por serem entidades públicas que comportam o Ensino Fundamental com o nível de 5ํano.

O delineamento metodológico foi caracterizado como estudo de caso, constituído por um único caso, por serem escolas com funcionamento do $1^{\circ}$ ao $5^{\circ}$ anos do Ensino Fundamental e que realizam a Prova Brasil//deb desde sua implementação, em 2005.

Esse método, assegura Yin (2010), facilita a compreensão dos fenômenos sociais complexos e em geral se aplica às diferentes áreas, como Ciências Humanas e Sociais, Psicologia, Sociologia, Economia, Política e Administração. O método preserva características holísticas e significativas dos acontecimentos da vida real, tais como: ciclos de vida individuais e outros. Para esse autor, o estudo de caso é uma estratégia metodológica de tipo exploratório, descritivo e interpretativo.

O número de participantes não foi definido previamente, visto que seriam todos os professores que trabalhassem nas duas escolas e que aceitassem participar da pesquisa e ainda atendessem aos critérios de inclusão e de exclusão. 
Foram critérios de inclusão: aceitar participar e ser, ou já ter sido, docente de turmas que realizam a Prova Brasil/Ideb durante um ano, pelo menos, de aplicação da prova. Sendo excluídos desta todos os sujeitos que não correspondessem aos critérios de inclusão e/ou se recusaram a assinar o Termo de Consentimento Livre e Esclarecido (TCLE).

Para identificarmos os sujeitos, fizemos o primeiro contato com as professores e identificamos que, em uma escola onde havia 15 docentes, apenas cinco atendiam aos critérios; na outra instituição, eram 12 professores, das quais somente três estavam de acordo com os critérios. Dessa maneira, nossa amostra se resumiu a oito docentes. Por questões éticas, as professoras tiveram suas identidades preservadas, sendo chamadas de Professoras, Professora 1, 2, 3 e assim sucessivamente.

Os dados foram coletados através de entrevista estruturada. A aplicação foi realizada no cenário de pesquisa de cada participante. Os docentes tiveram o tempo que consideraram necessário para responder às perguntas, tendo apenas que as responder individualmente.

A análise de dados foi realizada a partir da análise temática de Minayo (2008), a qual consiste em identificar os núcleos de sentidos que compõem uma comunicação, compreendida e interpretativa, considerando a subjetividade dos sujeitos.

Por fim, os participantes foram informados dos procedimentos éticos em conformidade com as orientações da Resolução n. 466/2012, do Conselho Nacional de Saúde (CNS).

\section{RESULTADOS E DISCUSSÕES}

Sob a premissa de que o sujeito não pode ser visto ou estudado de maneira isolada, mas sim situado em um contexto histórico, social e cultural construído e/ou reconstruído no âmbito da formação pessoal e profissional de maneira singular e plural, tecemos nossa análise interpretativa (LARROSA, 2015; TARDIF, 2014).

Em consonância com essa visão, dialogamos com oito professoras que ministravam aulas em turmas de $5^{\circ}$ ano, com formação em Pedagogia e titulação de especialistas. No que tange ao tempo de regência de turma de $5^{\circ}$ ano, as docentes tinham entre um e oito anos de experiência. 
As escolas nas quais ensinam são instituições públicas situadas em bairros de baixo Índice de Desenvolvimento Humano (IDH), e estão inseridas no programa de avaliação em larga escala desde sua implementação no Brasil.

Nos parágrafos seguintes, anunciamos os depoimentos das participantes da pesquisa ancorados na literatura da área.

Todas as participantes afirmaram que a Prova Brasil/ldeb provoca alterações no contexto escolar, ocasionando mudanças. Vejamos alguns argumentos:

Ocasiona mudanças no currículo da escola, no planejamento anual, no plano de ensino, na metodologia utilizada, na organização dos alunos em sala e na avaliação da aprendizagem. (Professora 1, grifamos).

Muda a rotina e a cultura da escola, porque o currículo altera o planejamento, nossa metodologia na sala de aula, porque tem que focar nos exercícios das provas. (Professora 4, grifamos).

Diante das afirmações, compreendemos que há um movimento de alterações que é permeado pelo processo de tomada de decisões exterior ao contexto escolar, que prescreve o trabalho docente, os interesses, as concepções e as experiências subjetivas.

Assim como menciona Jiménez Jaén (1998), citado por Contreras (2002), é frequente a determinação cada vez mais detalhada do currículo a ser adotada nas escolas, a avaliação dos alunos, a transformação dos processos de ensino em microtécnicas dirigidas à consecução de aprendizagens concretas perfeitamente estipuladas e definidas de antemão, os projetos curriculares nos quais se estipula perfeitamente tudo o que deve fazer o professor passo a passo ou, em sua carência, os textos e os manuais didáticos que devem fazer.

Isso se reflete no profissionalismo docente, reduzindo seu papel ao cumprimento de prescrições extremamente determinadas, perdendo de vista o conjunto e o controle sobre sua tarefa (CONTRERAS, 2002). Consideramos esses dados preocupantes, por inferir no currículo da escola, moldando-o às necessidades de se obter êxito na Prova Brasil//deb. Assim, o planejamento, por exemplo, que deveria ser uma ação reflexiva, resume-se a uma agregação de conteúdos esculpidos pelo Estado regulador.

Investigamos se havia disciplinas prejudicadas por conta das avaliações externas e identificamos que cinco participantes afirmaram que algumas disciplinas eram 
prejudicadas e três professoras julgaram que não havia prejuízo, como podemos identificar nos seguintes depoimentos:

Não há prejuízo nas outras disciplinas. Há momentos extras nas disciplinas de Português e Matemática. (Professora 1, grifamos).

Há prejuízo principalmente em Ciências, que só fica com uma aula por semana, isso quando não cai num feriado. (Professora 3, grifamos).

Algumas vezes deixamos a desejar em Ciências, devido ao tempo que dedicamos à linguagem. (Professora 4, grifamos).

História, Geografia, Ciências. O professor detém mais na escrita, leitura e matemática. (Professora 7, grifamos).

Mediante as falas, observamos que a ênfase dada à dimensão cognitiva nas disciplinas de Português e de Matemática induz a um estreitamento curricular e a uma centralização do fazer docente, ao passo que restringe o papel do profissional diante dos demais conteúdos do programa escolar, gerando um desconforto no professor.

Pensando pela lógica capitalista, que favorece a indústria da competição e cria um sistema de instabilidade no fazer docente, como assinalam Correia e Matos (2002), acreditamos que as duas disciplinas, por mais relevantes que sejam, não são suficientes para avaliar o rendimento do aluno e consequentemente o desempenho e a formação do professor, e sim negligencia a amplitude dos saberes docentes e seu profissionalismo, ao passo que nega a importância singular de todas as disciplinas que compõem um programa escolar e submetem o professor a regime de trabalho explorador.

Destinar maior tempo às disciplinas de Português e de Matemática, em virtude da avaliocracia', favorece uma instabilidade que gera poder e, ao mesmo tempo, desestabiliza a classe de professores, assim como cria subclassificações dos profissionais em uma mesma instituição escolar, favorecendo, nestes termos, jogo de poder discursivo, como assinala Foucault (2013, p. 8):

Suponho que em toda sociedade a produção do discurso é ao mesmo tempo controlada, selecionada, organizada e redistribuída por certo número de procedimentos que têm por função conjurar seus poderes e perigos, dominar seu acontecimento aleatório, esquivar sua pesada e temível materialidade.

1 Constituída como dispositivo ideológico que induz ao processo de desvalorização profissional por culpabilizar o professor pelo baixo desempenho do aluno (CORREIA; MATOS, 2002).

Educação \& Formação, Fortaleza, v. 4, n. 11, p. 161-178 maio/ago. 2019

DOI: https://doi.org/10.25053/redufor.v4i11.896

http://seer.uece.br/redufor 
Ao se inserir a política de avaliação externa, a educação escolar passa a ser mecanismo de controle e de regulação centrada no modelo que visa resultados rápidos, desse modo "[...] todo sistema de ensino é uma maneira política de manter ou de modificar a apropriação dos discursos, com os saberes e os poderes que eles trazem consigo" (FOUCAULT, 2013, p. 41).

Ao indagarmos sobre a frequência do uso de simulados/testes para preparar os alunos para a Prova-Brasil//ldeb, cinco professoras afirmaram usar um simulado por semana, duas declararam realizar três simulados por semana e apenas uma disse ser mensal. Seguem alguns depoimentos: "Mensal. Quando se aproxima da data, passa a ser semanal" (Professora 2); "Três simulados por semana” (Professora 5); "Um simulado por semana, todas as sextas-feiras" (Professora 8).

Essa frequência de aplicação de simulados é preocupante, posto que, há, na escola, um currículo muito vasto que deveria contemplar as necessidades dos alunos, em suas dimensões sociais, culturais, cognitivas e psicopedagógicas. Além disso, também castra a autonomia do professor em planejar suas leituras e seus conhecimentos pensando na qualidade do ensino.

A avaliação externa da educação básica e da gestão do sistema público de ensino por resultados e incentivos gera os piores efeitos sobre o ato educativo, sobre 0 professor, sobre a criança e sobre a própria gestão educacional (PASSONE, 2015).

Menegão (2016) realizou um estudo em Cuiabá, Mato Grosso, intitulado os impactos da avaliação em larga escala nos currículos escolares e constatou em seus resultados que a avaliação externa tem impactado na configuração do currículo escolar em demasia para os testes, comprometendo a qualidade da educação. Tal estudo corrobora a presente investigação, na medida em que a avaliação externa provoca alterações no currículo escolar e causa impactos na educação.

Quando questionamos as pedagogas sobre a relação teoria-prática nas estratégias metodológicas das avaliações externas, elas relataram:

É uma simulação da prova. É a prática na teoria, porque nós pegamos as anteriores, estruturamos para selecionar o conteúdo da aula. (Professora 2).

É definido um conteúdo que deve ser trabalhado em sala e esse conteúdo é cobrado nas avaliações. (Professora 4).

Educação \& Formação, Fortaleza, v. 4, n. 11, p. 161-178 maio/ago. 2019 
A metodologia adotada na construção e aplicação dos testes da Prova Brasil/ldeb é adequada para avaliar redes ou sistemas de ensino, e não alunos individualmente. (Professora 8).

As participantes evidenciaram a vinculação entre teoria e prática gerada por tensões e normatizações que tornam a educação um acontecimento ainda mais difícil, aumentando os mecanismos de controle e de regulação, que impossibilitam a ação pedagógica refletida e entendida como racionalidade pedagógica.

Ancoramo-nos em Freire (1981, p. 135), que ratifica que: "[...] separada da prática, a teoria é puro verbalismo inoperante; desvinculada da teoria, a prática é ativismo cego. Por isso é que não há práxis autêntica fora da unidade dialética ação-reflexão, teoria-prática". Essa articulação alicerça os saberes teóricos constitutivos do fazer pedagógico, tendo em vista a qualificação do professor na área do ensino e da aprendizagem (THERRIEN, 2014).

Sacristán (1999) destaca que a relação teoria-prática tem implicações e sentido em questões políticas, culturais e sociais, que a situam em contexto mais amplo, no qual intervêm outros agentes, inclusive à margem da tomada de decisões no sistema educativo.

Nessa práxis, também estão imbricadas as dimensões da formação do professor, perpassando pelo seu profissionalismo e pelas transposições didáticas que o docente implica sobre os conteúdos para torná-lo compreensível ao entendimento do aluno, sendo esse processo limitado pela desconstrução do trabalho pedagógico na reduzida tarefa de se aplicar testes como forma de aquisição de conhecimento.

Como menciona Sacristán (1999), as dimensões críticas têm distanciado a relação e a percepção recíproca entre teoria e prática, situando-as à margem de determinadas desigualdades e relações de poder.

No penúltimo item, questionamos as professoras se o sistema de avaliação externa contribui ou atrapalha com o seu profissionalismo. Constatamos diferentes pontos de vista, mas que convergiram para um posicionamento denunciador, mesmo que ainda muito tímido, como notamos nos depoimentos representados adiante:

Acho que atrapalha um pouco, pois temos que frisar bem, se dedicar ao conteúdo como Português e Matemática, mas a gente sabe que ensinar e ser um bom professor é muito mais que isso. (Professora 2, grifamos).

Educação \& Formação, Fortaleza, v. 4, n. 11, p. 161-178 maio/ago. 2019 
Contribuir para você saber lidar com uma eterna corrida contra o tempo e você se torna mais ágil. (Professora 3, grifamos).

Não contribui nem atrapalha para o profissionalismo, mas interfere na metodologia de trabalho e na autonomia do professor. (Professora 6, grifamos).

A fala representada pela Professora 2 assume um posicionamento contrário à forma como é imposto o sistema Prova Brasil//deb, posto que esta reflete a dimensão do que é ser professor.

Para ratificar os depoimentos, invocamos Gauthier et al. (1998), ao conduzir as condições essenciais para o professor desempenhar seu ofício, o que nos traz discussões sobre o contexto de um ofício sem saberes e saberes sem ofício. Nos dados de que dispõem, os autores afirmam que não basta o professor conhecer o conteúdo, haja vista que está imbricado em muitas outras relações no processo de ensino e de profissionalismo.

O sistema Prova Brasil//deb "[...] envolve sempre o risco de emissão de um juízo de valor sobre os professores", uma vez que torna público o desempenho dos alunos associando o fracasso ou sucesso ao trabalho pedagógico do profissional" (CORREIA; MATOS, 2002, p. 120).

A Professora 3 afirmou não atrapalhar, entretanto revelou uma "[...] eterna corrida contra o tempo [...]' que não garante a formação de um profissional críticoreflexivo, estando, pois, não tão distante do primeiro e do último depoimento. Nesse enfoque, Sacristán (1999) ressalta que as atitudes pragmáticas acentuam-se para que seja possível atender às supostas demandas do sistema capitalista, o qual requer agilidade para a resolução das questões e não coloca a reflexão crítica sobre a realidade como requisito.

O professor, ao passo que atende à demanda imensa de conteúdo, principalmente quando se aproxima dos períodos das avaliações externas, subordina-se a um sistema neoliberal que afeta a consciência crítica, por isso não pode se deixar levar pela dinâmica política dessa interferência.

No depoimento represado pela Professora 6, embora não tenha afirmado que atrapalha, também não negou, assumindo ainda que "[...] interfere na metodologia e na autonomia [...]', no entanto não esclareceu se de forma positiva ou negativa.

Educação \& Formação, Fortaleza, v. 4, n. 11, p. 161-178 maio/ago. 2019 
Fazemos uma analogia fundada no estudo desenvolvido por Fernandes, Figueiredo e Leite (2017), intitulado "Avaliação externa de escolas: do discurso às práticas, uma análise focada em Portugal e em Inglaterra", o qual, ainda que não tenha sido desenvolvido no Brasil, assemelha-se ao sistema de avaliação brasileira e corrobora nossa investigação ao averiguar que, embora a avaliação das escolas tenha surgido como um processo claro, abrangente e formativo, sua concretização se afasta dessa concepção. As autoras concluem que, em ambos os países pesquisados, os processos de avaliação denunciam uma visão redutora da educação e uma desvalorização do trabalho dos professores, ao sobrevalorizarem os resultados escolares dos alunos.

A política de avaliação, da forma que está ocorrendo, especialmente a Prova Brasil//deb, tem contribuído para manter os profissionais da educação presos à teia de responsabilização, de meritocracia e de desprofissionalização (MENEGÃO, 2016).

No último item, indagamos se as participantes consideravam que a Prova Brasil/ldeb reduzia sua autonomia e/ou dificultava seu papel de professoras reflexivas. As respostas conduziram a três núcleos: reduz a autonomia; não reduz; e reduz parcialmente. Identificamos a seguir nos registros das professoras:

\footnotetext{
Penso que sim, porque eu não posso fazer o que entendo que é melhor para - meu aluno. Quem sabe o que é melhor para o meu aluno e para a escola somos nós, professores, que estamos todos os dias no chão da escola. Não sei se respondi o que pediu, mas é assim que penso. (Professora 2, grifamos).
}

Não retira a autonomia, mas compromete um pouco, pois somos obrigados a seguir um modelo de avaliação e um conteúdo específicos. (Professora 4, grifamos).

Não. Me ajuda a refletir melhor. Ficamos mais atentos ao desenvolvimento do aluno. Passamos a nos cobrar mais. Buscamos mais estratégias, analisamos mais 0 aluno individualmente. (Professora 7 , grifamos).

No depoimento da Professora 2, interpretamos uma subtração no trabalho docente, fato que conduz a uma proletarização ${ }^{2}$ profissional. A Professora 4 , ainda que tenha negado essa subtração por meio da perda da autonomia, admitiu que o trabalho docente é comprometido, argumento este que sustenta o controle ideológico e a perda, mesmo que parcial, da autonomia, comprometendo também seu profissionalismo.

2 Expressão pautada na perda por parte dos professores daquelas qualidades que faziam deles profissionais ou ainda a deterioração daquelas condições de trabalho nas quais depositamos suas esperanças de alcançar tal status (CONTRERAS, 2002).

Educação \& Formação, Fortaleza, v. 4, n. 11, p. 161-178 maio/ago. 2019

DOI: https://doi.org/10.25053/redufor.v4i11.896

http://seer.uece.br/redufor 
Diferentemente, a Professora 7 declarou que participar do processo da Prova Brasi//ldeb não gera perda, ao contrário, incentiva a rigorosidade de controle técnico-pedagógico.

Frente aos posicionamentos, Contreras (2002, p. 33) alude que "[...] o trabalho docente sofre uma subtração progressiva de uma série de qualidade que conduziram os professores à perda de controle e sentido sobre o próprio trabalho, ou seja, à perda da autonomia". São perdas ocasionadas pelos contextos de trabalho em que o docente está inserido; o que está em jogo na perda da autonomia dos professores é tanto o controle técnico, no caso das avaliações, como a desorganização ideológica, na qual possam se ver mergulhados (CONTRERAS, 2002).

As professoras, ao pensarem no ato de ensinar dentro do contexto no qual estavam inseridas, refletiram numa perspectiva dialética que as conduziu à condição de racionalização ${ }^{3}$ a que estavam submetidas.

Uma formação comprometida com a reflexividade traz como centralidade do processo de formação profissional a reconciliação entre teoria e prática, ensino e pesquisa, em que a relação de mediação pedagógica entre o docente e 0 aprendiz acontece (THERRIEN, 2014). Em consonância com essa visão, Sacristán (1999, p. 44) reforça a importância de recuperar o "sentido da ação" e considerar suas implicações morais e os compromissos políticos assumidos. Nas palavras de Gauthier et al. (1998, p. 19), "[...] no contexto escolar atual, esse trabalho de pesquisa e reflexão constitui uma necessidade fundamental na profissionalização do ensino", assim como no profissionalismo do professor em pleno exercício.

Nesse envolvimento, o saber do professor passa a um segundo plano, ficando subordinado a uma relação pedagógica centrada nas determinações das avaliações externas. Essa situação gera um processo de desqualificação profissional, ao passo que Ihes obriga a seguir um modelo de avaliação e um conteúdo específicos, enfraquecendo o poder decisivo e reflexivo do professor.

Posto isso, a avaliação incide sobre produtos cognitivos da ação pedagógica, desempenhando um conjunto de missões que transcendem a simples emissão de um juízo de valor sobre as competências cognitivas dos alunos. Constitui, sim, um

3 Os processos de racionalização se referem àqueles pelos quais a ação se submete ao planejamento prévio, segundo o qual se determinam as regras e procedimentos lógicos de decisão, bem como as metas que devem ser alcançadas (CONTRERAS, 2002).

Educação \& Formação, Fortaleza, v. 4, n. 11, p. 161-178 maio/ago. 2019

DOI: https://doi.org/10.25053/redufor.v4i11.896

http://seer.uece.br/redufor 
dispositivo de legitimação compensatória da intervenção política do Estado avaliador, que cria tanto disposições de hierarquização das escolas, em função de um desempenho que só pode ser qualificado através dos seus produtos cognitivos, como contribui para a produção de disposições que tendem a desvalorizar e a desqualificar as dimensões do saber docente e o profissionalismo docente (CORREIA; MATOS, 2002).

\section{CONSIDERAÇÕES FINAIS}

Compreendemos que a avaliação tem sua importância no contexto escolar, mas não podemos negar as causas e as consequências de ambivalência que ela provoca. Com este diálogo investigativo, é possível afirmar que a política de avaliação está incrustada nessas escolas, de forma indutora, interferindo no trabalho docente, no currículo e no profissionalismo do professor. Nestes termos, a formação profissional do professor está subordinada a um sistema de avaliação que funciona como legitimador de determinados conjuntos de saberes e de práticas pedagógicas, por conseguinte, poderes.

Este artigo debruçou-se sobre os processos de avaliação externa das escolas, na sua concepção legal e na concretização nesses ambientes educacionais. Os dados apontados permitiram concluir que o discurso presente nos documentos legais apontam para a avaliação como um instrumento a serviço da qualidade da escola e da melhoria da educação. No entanto, os dados das entrevistas revelaram uma avaliação que se afasta de uma abordagem formativa e abrangente para assumir um sentido marcado pela função de controle e de regulação.

Propomos que as Secretarias de Educação realizem encontros com os professores, alunos e pais para dialogarem sobre pontos positivos e negativos da inserção das avaliações externas nas escolas; que as verbas para a melhoria da educação não sejam subordinadas ao rendimento dos alunos, mas sim que haja investimento nas escolas e na formação dos professores desvinculado dessa subordinação; e que os responsáveis pelas políticas de avaliação sejam mais cautelosos no sentido de gerarem alterações no currículo, possibilitando o discurso ético com a comunidade escolar. Sugerimos a realização de mais estudos que fomentem dados

Educação \& Formação, Fortaleza, v. 4, n. 11, p. 161-178 maio/ago. 2019 
expressivos sobre a realidade das escolas e suas relações concretas com os sistemas de avaliação.

Concluímos, no inacabamento da ação investigativa, que a vinculação entre avaliação e profissionalismo acontece de forma precária, por meio de implicações diretas no currículo escolar que refletem e dificultam a autonomia das professoras e cria empecilhos à práxis pedagógica.

\section{REFERÊNCIAS}

BONFIM, M. I. R. M. A regulação do trabalho docente na Educação Básica: as prescrições dos organismos internacionais nos anos 2000. In: REUNIÃO ANUAL DA ANPEd, 33., 2010, Caxambu. Anais... Caxambu: ANPEd, 2010. p. 1-5.

BRASIL. Lei n. 9.394, de 20 de dezembro de 1996. Estabelece as Diretrizes e Bases da Educação Nacional. Diário Oficial [da] República Federativa do Brasil, Poder Executivo, Brasília, DF, 21 dez. 1996.

BRASIL. Plano de Desenvolvimento da Educação/PDE. Disponível em: <http://portal. mec.gov.br/dmdocuments/saeb_matriz2.pdf>. Acesso em: 16 de out. 2017.

BRASIL. Portaria n. 69, de 4 de maio de 2005. Dispõe sobre a composição das Comissões Multidisciplinares de Avaliação de Cursos e sua sistemática de atuação. Diário Oficial [da] República Federativa do Brasil, Poder Executivo, Brasília, DF, 5 maio 2005.

BRASIL. Provinha Brasil. Disponível em: <http://inep.gov.br/provinha-brasil>. Acesso em: 8 de jun. 2017.

BRASIL. Resolução n. 466, de 12 de dezembro de 2012. Diretrizes e normas regulamentadoras de pesquisas em seres humanos. Diário Oficial [da] República Federativa do Brasil, Poder Executivo, Brasília, DF, 13 dez. 2012.

BRASIL. Saeb-Prova Brasil 2011. Avaliação do rendimento escolar. Questionário do professor. Brasília, DF: MEC, 2011. Disponível em: <http://download.inep.gov.br/educa cao_basica/prova_brasil_saeb/questionarios/2013/questionario_professor.pdf>. Acesso em: 23 ago. 2015.

CONTRERAS, J. Autonomia de professores. São Paulo: Cortez, 2002.

CORREIA, J. A.; MATOS, M. Solidões e solidariedades nos quotidianos dos professores. Portugal: ASA, 2002.

Educação \& Formação, Fortaleza, v. 4, n. 11, p. 161-178 maio/ago. 2019

DOI: https://doi.org/10.25053/redufor.v4i11.896

http://seer.uece.br/redufor 
DALBEN, Â. I. L. F. Avaliação sistêmica. Revista Presença Pedagógica, Belo Horizonte, v. 11, n. 65 , p. 74-80, 2005.

FERNANDES, P.; FIGUEIREDO, C.; LEITE, C. Avaliação externa de escolas: do discurso às práticas: uma análise focada em Portugal e em Inglaterra. Revista Meta: Avaliação, Rio de Janeiro, v. 9, n. 25, p. 1-31, 2017.

FOUCAULT, M. A ordem do discurso: aula inaugural no Collége de France, pronunciada em 2 de dezembro de 1970. 23. ed. São Paulo: Loyola, 2013.

FREIRE, P. Ação cultural para a liberdade. 5. ed. Rio de Janeiro: Paz e Terra, 1981.

FREITAS, L. C. Qualidade negociada: avaliação e contrarregulação na escola pública. Educação \& Sociedade, Campinas, v. 26, n. 92, p. 911-933, 2005.

GAUTHIER, C. et al. Por uma teoria da pedagogia: pesquisas contemporâneas sobre os saberes docentes. ljuí: Unijuí, 1998.

IMBERNÓN, F. Formação docente e profissional: formar-se para a mudança e a incerteza. São Paulo. 9. ed. Cortez, 2010.

LARROSA, J. Tremores: escritos sobre experiência. Belo Horizonte: Autêntica, 2015.

MENEGÃO, R. C. S. G. Os impactos da avaliação em larga escala nos currículos escolares. Práxis Educativa, Ponta Grossa, v. 11, n. 3, p. 641-656, 2016.

MINAYO, M. C. S. O desafio do conhecimento: pesquisa qualitativa em saúde. 11. ed. São Paulo: Hucitec, 2008.

PASSONE, E. F. K. Notas psicanalíticas: os discursos contemporâneos acerca da avaliação educacional no Brasil. Educação e Pesquisa, São Paulo, v. 41, n. 1, p. 185-201, 2015.

SACRISTÁN, J. G. O currículo: uma reflexão sobre a prática. 3. ed. Porto Alegre: Artmed, 2000.

SACRISTÁN, J. G. Poderes instáveis em educação. Porto Alegre: Artes Médicas Sul, 1999.

SAVIANI, D. O ensino de resultados. Folha de S. Paulo, São Paulo, 29 abr. 2007.

TARDIF, M. Saberes docentes e formação profissional. 17. ed. Petrópolis: Vozes, 2014.

THERRIEN, J. Parâmetros de pesquisa científica do pesquisador de sua práxis docente - articulando didática e epistemologia da prática. In: ENDIPE, 17., 2014, Fortaleza. Anais... Fortaleza: UECE, 2014.

YIN, R. K. Estudo de caso: planejamento e métodos. 4. ed. Porto Alegre: Bookman, 2010. 
Maria Adriana Borges dos Santos (Brasil, Ceará, Fortaleza) - Universidade Estadual do Ceará (UECE)

Doutoranda em Educação pela UECE. Integrante do Grupo de Estudos e Pesquisa em Educação Física Escolar (Gepefe) e do Educação, Cultura Escolar e Sociedade (Educas). Professora efetiva da rede municipal de Maracanaú/CE.

Lattes: <http://lattes.cnpq.br/4063739427583175>.

E-mail: <madriborges@hotmail.com>.

Heraldo Simões Ferreira (Brasil, Ceará, Fortaleza) - Universidade Estadual do Ceará (UECE)

Pós-Doutor em Educação Física Escolar pela Universidade Estadual Paulista Júlio de Mesquita Filho (Unesp). Líder do Grupo de Estudos e Pesquisa em Educação Física Escolar (Gepefe). Conselheiro no Conselho Regional de Educação Física (CREF5). Professor adjunto da UECE.

Lattes: <http://lattes.cnpq.br/4687823647729315>.

E-mail: <heraldo.simoes@uece.br>.

Luiza Lúlia Feitosa Simões (Brasil, Ceará, Fortaleza) - Universidade Estadual do Ceará (UECE) Doutoranda em Educação pela UECE. Integrante do Grupo de Estudos e Pesquisa em Educação Física Escolar (Gepefe) e do Núcleo de Documentação, Informação, História e Memória da Enfermagem no Ceará (Nudihmen). Professora da Secretaria Municipal da Educação de Fortaleza. Professora formadora da Universidade Aberta do Brasil (UAB/UECE).

Lattes: <http://lattes.cnpq.br/2599825373328574>.

E-mail: <luizalfsimoes@gmail.com>.

Recebido em 25 de outubro de 2017.

Aceito em 14 de outubro de 2018. 